\title{
Shear strength features of unsaturated clayey sand by lab test
}

\author{
Qingyan Tian $^{1} \cdot$ Nigui Qian ${ }^{2} \cdot$ Jiantong Zhang ${ }^{3}$
}

Received: 29 May 2016/Accepted: 20 July 2016/Published online: 28 July 2016

(C) Springer International Publishing Switzerland 2016

\begin{abstract}
To study the shear feature of the clayey sand subgrade, the equations of soil-water characteristic curve with different net mean stresses were established based on laboratory test and non-linear elastic theory. The laboratory result shows that the net mean stress has significantly affected on the soil-water characteristic curve shape. The greater the net mean stress, the smaller moisture content of soil. The shear features of clayey sand were also figured out using triaxial equipment with mini air and water pressure sensors in non-drained and non-exhaust state. The results of research indicate that the net confining pressure and moisture content have significant effect on the strength, deformation, and yield feature of unsaturated clayey sand. The shear strength increases with the growth of net confining pressure in case of constant moisture content. The cohesion and friction angle of soil become larger with the increase of moisture content less than optimum content; while the water content is greater than the optimum water content, they show the opposite trend. The unsaturated clayey sand shows obvious dilatancy deformation in shearing. In the phase of shear contraction, the shear stress increases with the growth of suction and net confining
\end{abstract}

Jiantong Zhang

tongtong01@126.com

Qingyan Tian

tqy0616@163.com

Nigui Qian

361309156@qq.com

1 Traffic Science and Technology of Guangdong Hualu Limited Company, Guangzhou, China

2 South China University of Technology, Guangzhou, China

3 School of Civil Engineering, Wuhan University, No. 299, Wuchang District, Wuhan, Hubei Province, China pressure, which declines after it reach the peak point. Results of this research will be a benefit for the engineer.

Keywords Unsaturated clayey sand - Shear strength · Soil-water characteristic curve (SWCC) - Stress-strain relationship · Dilatancy

\section{Introduction}

Clayey sand spreads in southern China and it is widely used in subgrade. During the construction, subgrade was compacted at optimum moisture content. It would reach to initial equilibrium then waves with season change after it is subjected to climatic and environmental factors. It is always in unsaturated state. The subgrade layers provide a substantial part of the overall structural capacity of the pavement system, especially for flexible pavements. Excess moisture, when combined with heavy traffic and moisture-susceptible materials, can induce structural distresses, which would dramatically increase life-cycle pavement costs. It is widely known that the characteristics of the unsaturated soil are strongly related to the change in suction $[1,13]$. Since the strength-suction-moisture relationship of the compacted soils at the initial conditions is different from that after, the influence of moisture and suction on the shear strength features of compacted soils need to be explored.

As traffic load on the pavement is transient, we assume that the shear strength and deformation change with the water content of subgrade under the undrained and unexhaust state. In addition, the stresses induced in a pavement system by traffic loads are highest in the upper layers and diminish with depth, the soil-water characteristic curve (SWCC) of clayey sand under net mean stress should be 
Table 1 The physical mechanics parameters of Guangdong province clayey sand

\begin{tabular}{lllllllll}
\hline Specific & $\begin{array}{l}\text { Max dry } \\
\text { gravity } \\
\text { density } \\
\left(\mathrm{g} / \mathrm{cm}^{3}\right)\end{array}$ & $\begin{array}{l}\text { Optimum moisture } \\
\text { content }(\%)\end{array}$ & NMC $W_{0}(\%)$ & \multicolumn{6}{l}{ Granularity (\%) } \\
\cline { 5 - 8 } & 1.90 & 13.5 & 9.6 & 10.39 & 19.58 & 32.46 & 22.75 & 14.82 \\
\hline 2.68 & 1.5 & & & $0.5-2$ & $0.2-0.5$ & $0.2-0.075$ & $<0.075$ \\
\hline
\end{tabular}

established first to understand the mechanical behaviors of unsaturated subgrade soil in the paper. Then using unsaturated soil testing techniques and micro-pore pressure sensor, pore air pressure and water pressure during the clayey sand shear process is determined by triaxial shear test device to study on the effect of the water content and dry density to shear strength and deformation features of unsaturated soil.

Based on the above analysis, it is very urgent to further research on the mechanical properties of unsaturated sandy soil, and it also has great practical value in engineering in China.

\section{Materials and methods}

\section{Physical mechanical parameters of clayey sand}

In this study, soil comes from Guangzhou-Foshan expressway widening project in Guangdong Province. The physical mechanical parameters of clayey sand are measured in the laboratory and given in Table 1, based on the specification of "Standard for soil test method (GB/T 50123)" and "Standard for engineering classification soil (GB/T 50145)". The soil is identified as clayey sand.

In this research, a four channel unsaturated consolidation apparatus which was developed by Chen et al. [2, 3] is used to measure parameters of the curve of Compression curve and SWCC. This device can be able to independently control (or measured) total stress, pore water pressure and pore gas pressure. Four soil samples were fabricated in the size of $6.18 \mathrm{~cm}$ (diameter) $\times 2 \mathrm{~cm}$ (height) with the dry density of $1.85 \mathrm{~g} / \mathrm{cm}^{3}$. Before the test, the samples are pumped to saturation, and weighted with an accuracy of $0.001 \mathrm{~g}$ weight, then put them into 1-4 channel of the apparatus by the introduction (seen Fig. 1). After samples are installed, loading begin and net vertical pressure applied in each channel with $0,100,200$ and $300 \mathrm{kPa}$, respectively. Matric suction is controlled by $25,50,75$, $100,150,200,300$ and $400 \mathrm{kPa}$. In this test, three stability criteria, which are vertical deformation less than $0.01 \mathrm{~mm}$ in every $2 \mathrm{~h}$, drainage quantity no more than $0.012 \mathrm{~cm}^{3}$ in every $2 \mathrm{~h}$, and the load stability time not less than $48 \mathrm{~h}$, which must be satisfied at the same time.

The shear strength and pore water pressure of unsaturated soil can be obtained using the unsaturated soil triaxial apparatus (USTA) under the condition of fixed vertical pressure and controlled suction and pressure (Fig. 2). The USTA is shown in Fig. 2 which has the following characteristics: (1) Higher suction can be applied. (2) Variable volume can be measured in high precision. (3) The function of internal and external pressure chamber can eliminate the error caused by the deformation of internal pressure chamber. (4) A measuring device of drainage volume is installed. (5) The pores pressure inside the soil can be controlled using USTA. The SWCC can be measured using USTA under wide range of suction.

Test method is described in the following. The moisture content of wet soil sample was calculated according to the design of dry density of the sample. Then, the wet soil sample was divided into five equal parts. The test sample was fabricated using a special device to compact the wet

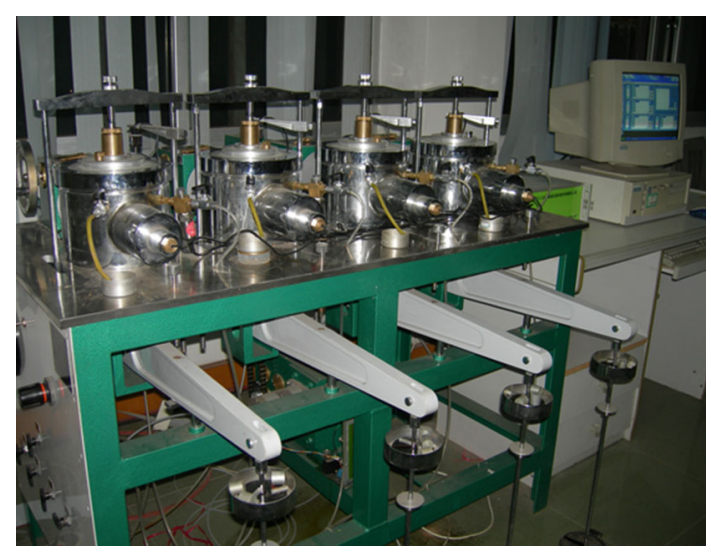

Fig. 1 Four channel unsaturated consolidation apparatus

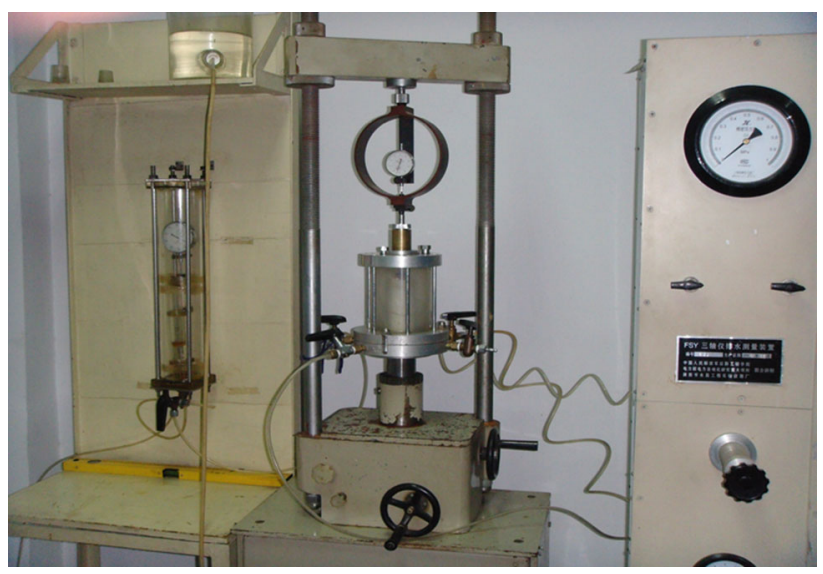

Fig. 2 The unsaturated soil triaxial apparatus (USTA) 
soil in five layers that was controlled with film set and steel ring. Finally, the sample was molded in the size of $3.91 \mathrm{~cm}$ (diameter) $\times 8 \mathrm{~cm}$ (height). The gas of test specimen was pumped until saturated suction before testing. According to the load path of triaxial compaction test, the test sample was loaded in four different stress paths. The net mean stress is $0,25,50$ and $100 \mathrm{kPa}$, respectively. When the net mean stress is $0 \mathrm{kPa}$ which indicates that the test sample is not suffered net mean stress.

\section{Soil-water characteristic curve}

The soil-water characteristic curve (SWCC) defines as the relationship between volumetric water content and a particular suction in the soil, and becomes a dominant relationship for understanding unsaturated soil behavior. A number of equations have been proposed to best-fit the SWCC empirically. The constitutive equations for volume change, shear strength, and flow through unsaturated soil have been studied in the past three decades. Based on Mechanistic Empirical Design [10], the shear strength, resilient modulus, and stiffness of New and Rehabilitated Pavement Structure were predicted by water content [4].

In [5], Fredlund and Raharjo recognized that the stress state of a soil has some influence on the SWCC. Vanapalli et al. $[11,12]$ examined the influence of the total stress state on the SWCC of a compacted fine-grained soil indirectly. Huang et al. [6] studied the yield locus of unsaturated soil on $\mathrm{p}-\mathrm{s}$ plane and determined the influence of net mean stress on unsaturated loss. Miao et al. [7, 8, 9] studied the influence of the stress state and wetting-drying cycles on the soil-water characteristic curve of Nanyang expansive soil in China. In this paper, net mean stress was taken as a variable to study the soil-water characteristic curve of unsaturated clayey sand by triaxial instrument.

To simulate the characteristics of compacted soil of subgrade, samples were compacted under different moisture content. Dry density of them was controlled at $1.85 \mathrm{~g} /$ $\mathrm{cm}^{3}$. Four group tests were conducted through different stress path according to triaxial shrinkage test to determine the SWCC. For each group, the net mean stress was set at $0,25,50$ and $100 \mathrm{kPa}$, respectively.

Test results were plotted in the relationship of w-s in Fig. 3, in which water content of unsaturated sample was calculated by deducting drainage water from initial water content during triaxial drainage consolidation test. It shows that the soil moisture content deceases with the increase of suction under the same net mean stress; In the case of certain suction, it decreases with the increase of net mean stress. The value of net mean stress has significant influence on the shape of SWCC. Three curves, in which net mean stresses were controlled at 0,25 and $50 \mathrm{kPa}$, can be divided into three sections with the

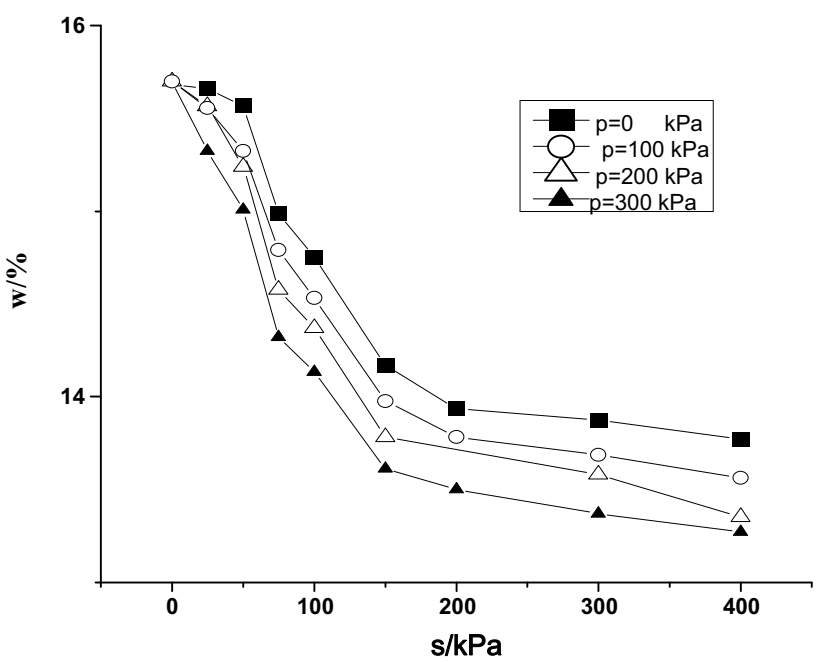

Fig. 3 Relationship between w and s under different net mean stress

increase in suction. Each section corresponds to the different states of unsaturated soil moisture. The first section is an initial flat section, when suction changes from 0 to $50 \mathrm{kPa}$, three curves almost coincide because of low suction and net mean stress. In this section, the soil is almost saturated, the value of suction is less than air intake, and the change of suction is very small. Air phase in soil is in closed state as bubbles suspending and flowing with water. The properties of soil in this state approach to that of saturated soil. When suction is in reach or more than air intake value, soil is in the second section, in which suction is from 50 to $200 \mathrm{kPa}$. This section corresponds to the segment decreased drastically in the soil-water characteristic curve. The air begins to enter the soil, and occupy the soil within the larger pore channels. Air is in the form of pore connectivity or partly connectivity patterns. With the suction increases, saturation of soil declines rapidly. The third section is the second flat segment in SWCC, in which suction is larger than $200 \mathrm{kPa}$. Air phase is in complete connectivity state. Since very little soil moisture, which is only filling small pore or pore corners, the suction of soil is very high. But significant increase of suction in this state only result in very little change in moisture content in soil, and it plays smaller and smaller role in the nature of unsaturated soil. The net mean stress was controlled at $100 \mathrm{kPa}$ which was divided into two sections. The boundary point is $s=175 \mathrm{kPa}$. The mechanics of the moisture and suction is same to the second section and the third segment of that $p$ was controlled at 0,25 and $50 \mathrm{kPa}$.

Usually, three stress tensors were used to express the stress state of an unsaturated soil. Two tensors, net total stress tensor $\left(\sigma_{i j}-u_{a} \delta_{i j}\right)$ and suction tensor $\left(u_{a}-u_{w}\right) \delta_{i j}$, also can be used assuming that there is no compression of soil particles. Here: $\sigma_{i j}, u_{a}, u_{w}$ are total stress tensor, pore 
air pressure, and pore water pressure, respectively. $\sigma_{i j}$ is Kronecker symbol. Triaxial stress state was expressed as follow:

$p=\frac{\sigma_{1}+\sigma_{2}+\sigma_{3}}{3}-u_{a}$

$q=\sigma_{1}-\sigma_{3}$

$s=u_{a}-u_{w}$,

where $p, q$ and $s$ are net mean stress, deviator stress, and suction, respectively; $\sigma_{1}, \sigma_{2}, \sigma_{3}$ are three principal stresses. Water phase volume strain of soil is defined as

$\varepsilon_{w}=\frac{\Delta V_{w}}{V_{0}}$

where $\Delta V_{w}$ is volume change of water in soil, and $V_{0}$ is the initial volume of soil.

In the three phase of unsaturated soil, the moisture content is expressed as

$w=w_{0}-\frac{1+e_{0}}{d_{s}} \varepsilon_{w}$,

where $w_{0}, e_{0}$, and $d_{s}$ are initial moisture content, initial porosity ratio, and relative density of soil sample. To simulate the soil-water characteristic curve of clayey sand, a non-linear elastic model of unsaturated soil proposed by Chen et al. [2] was used in this study.

$\mathrm{d} \varepsilon_{w}=\frac{\mathrm{d} p}{K_{w t}}+\frac{\mathrm{d} s}{H_{w t}}$,

where $K_{w t}$ is the tangent bulk modulus of water associated with net mean stress; $H_{w t}=\ln 10 \frac{s+p_{\text {atm }}}{\lambda_{w}(p)}$ is the tangent bulk modulus of water associated with suction, in which, $\lambda_{w}(p)$ is a constant, so $H_{w t}$ is only related to current suction. If the expression of $H_{w t}$ is substituted into Eq. (4) then integrating the formulations, an equation of all variables can be obtained:

$\varepsilon_{w}=\frac{p}{K_{w t}}+\frac{\lambda_{w}(p)}{\ln 10} \ln \left(\frac{s+p_{\mathrm{atm}}}{p_{\mathrm{atm}}}\right)$,

substituted Eq. (5) into Eq. (3), an equation of generalized SWCC can be obtained,

$w=w_{0}-\frac{1+e_{0}}{d_{s}}\left[\frac{p}{K_{w t}}+\frac{\lambda_{w}(p)}{\ln 10} \ln \left(\frac{s+p_{\mathrm{atm}}}{p_{\mathrm{atm}}}\right)\right]$.

The general form of the above equation is

$w=w_{0}-a p-b \ln \left(\frac{s+p_{\mathrm{atm}}}{p_{\mathrm{atm}}}\right)$,

where $a=\frac{1+e_{0}}{d_{s} K_{w t}}, b=\frac{1+e_{0}}{d_{s}} \frac{\lambda_{w}(p)}{\ln 10}, a$ and $b$ are constants, $p_{\text {atm }}$ is air pressure.

According to drainage, suction, pressure and net mean stress test data, the coefficient of the equation was derived from a multiple regression, $a=0.00302, b=2.0152$. The data from regression was compared with that from test, as shown in Fig. 4. It can be found from Eq. (9) that the best fit of the SWCC is under the net mean stress. Using Eq. (9), moisture content in subgrade soil can be estimated from suction of the soil, which has an advantage of avoiding determining the parameters of unsaturated soil from triaxial test.

\section{Results and discussion}

Expressway is in the state of non-drained and non-exhaust because of the transient traffic load. The characteristic shear feature of unsaturated clayey sand subgrade is very important to understand how it works.

Fifteen shear test samples were conducted by unsaturated triaxial equipment in five groups; Pore water pressure and pore air pressure were also determined using minisensors of water pressure and air pressure.

\section{Stress and axial strain relationship}

In Fig. 5, the shear stress and axial strain curves of clayey sand with same dry density show different characteristic with the change of net confining pressure and moisture content.

In Fig. 5, it indicates that moisture content and net confining pressure are the important factors to shear strength of clayey sand, and the optimum moisture content is also a turning point of the shear strength developing.

It can be see that deviator stress increases with net confining pressure when moisture content remains at same level. At low confining pressure, the basic performance of soil shows the weak strain hardening character, shear stress increasing slowly with the axial strain growth. It appears soil shear strength peak at lower axial strain. When the confining pressure is growing, such as at $200 \mathrm{kPa}$ in (c) and (d) of Fig. 5, the soil shows weak strain softening behavior in which shear stress increases rapidly with the axial strain increasing and the soil strength increases with confining pressure and up to a peak value at larger axial strain.

At the same net confining pressure, the relationship between moisture content and deviator stress developing in different trends before and after optimum moisture content. When moisture content lower than optimum moisture content, deviator stress significantly increases with the moisture content. The friction between soil particles at lower moisture is larger than that at higher moisture content, on the other hand, cohesion of the soil increases with moisture content. Deviator stress will decrease when moisture content larger than optimum moisture content. In this situation, soil particles swell with water content, the 


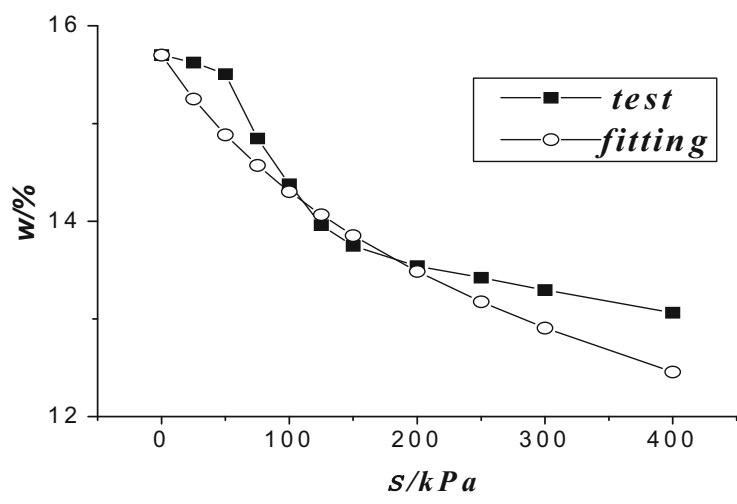

(a) $\mathrm{p}=0 \mathrm{kPa}$

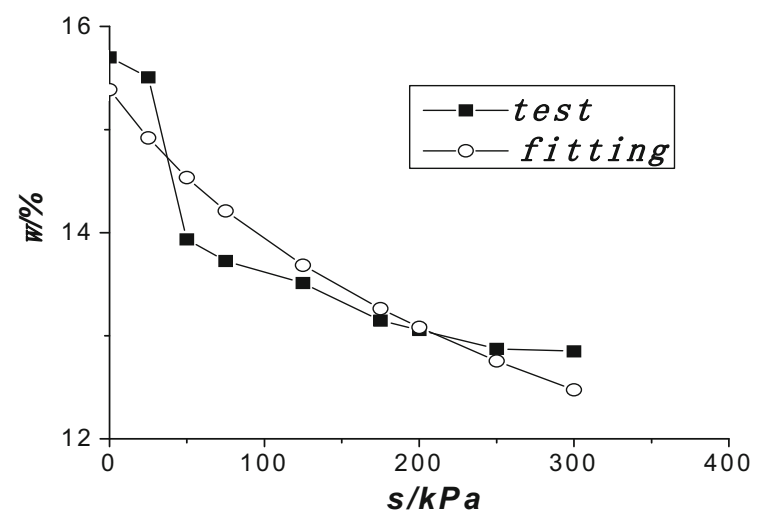

(c) $\mathrm{p}=200 \mathrm{kPa}$

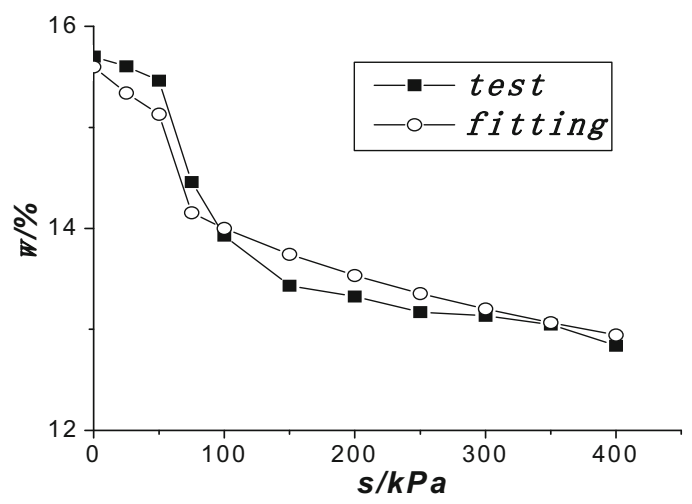

(b) $\mathrm{p}=100 \mathrm{kPa}$

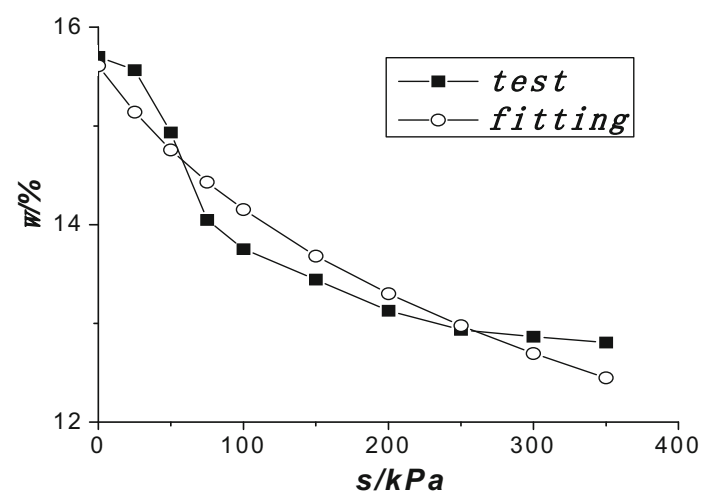

(d) $\mathrm{p}=300 \mathrm{kPa}$

Fig. 4 Relationship between test data and fitting under different net mean stress

skeleton of soil softens too, thus the modulus of soil declines with increasing of water content. As a result, the cohesion and internal friction angle of the soil decline with the increase of water content.

Figure 6 shows the cohesion and internal friction angle developing with moisture content growth in nondrained and non-exhaust state at the density of $1.85 \mathrm{~g} /$ $\mathrm{cm}^{3}$. Both of the parameters show peak value at the optimum moisture content. When moisture content less than the optimum content, the cohesion and internal friction angle increase slowly with the moisture content growth and the internal friction angle of clayey sand growth more slowly than cohesion, but decrease significantly when moisture content larger than the optimum content.

\section{Dilatancy of clayey sand}

Figure 7 is the curve of volume change with axial strain increase at same density and different moisture content. It shows obviously dilatancy of clayey sand including volume contraction and expansion. In the same density and moisture content, the dilatancy of clayey sand significantly decreases with the increase of net confining pressure. When dry density is the same, clayey sand shows dilatancy waning, while the moisture content increases.

\section{Pore water pressure and pore air pressure}

Figure 8 is the relationship between axial strains and pore water and air pressure. Air pressure and water pressure are shown in solid symbol and hollow symbol, respectively. Pore water pressure and pore air pressure are closely related to volume change of specimen. The peak of volume change corresponds to the peak of pore air pressure in Fig. 8. It develops at same trend with volume change. As shear proceeds, pore water pressure and pore air pressure increase first and then decrease. With the occurrence of dilatancy, pore air pressure and pore water pressure curves gradually separate. At this moment, moisture content of specimen does not change, but the volume increases, thus suction of soil increases correspondingly. In the case of the same moisture content, the greater the net confining pressure, pore air pressure and pore water pressure is also greater. 
Fig. 5 The curve of shear stress and axial strain at density of $1.85 \mathrm{~g} / \mathrm{cm}^{3}$

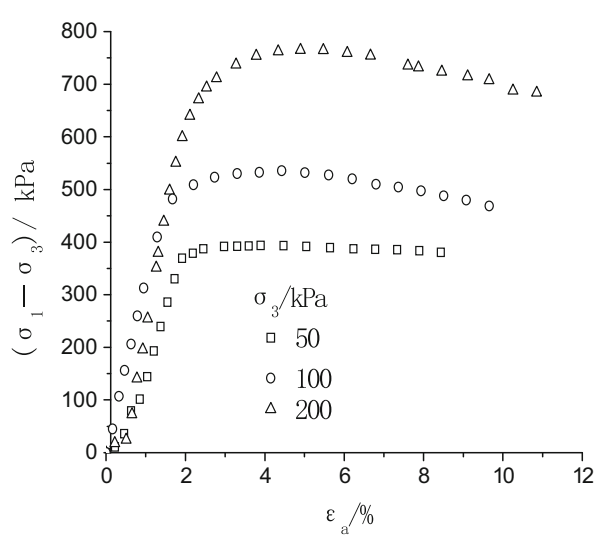

(a) $\mathrm{w}=11 \%$

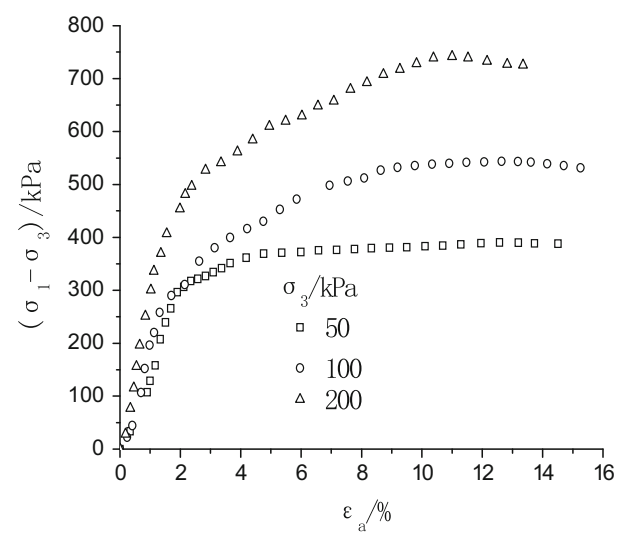

(c) $\mathrm{w}=14.83 \%$

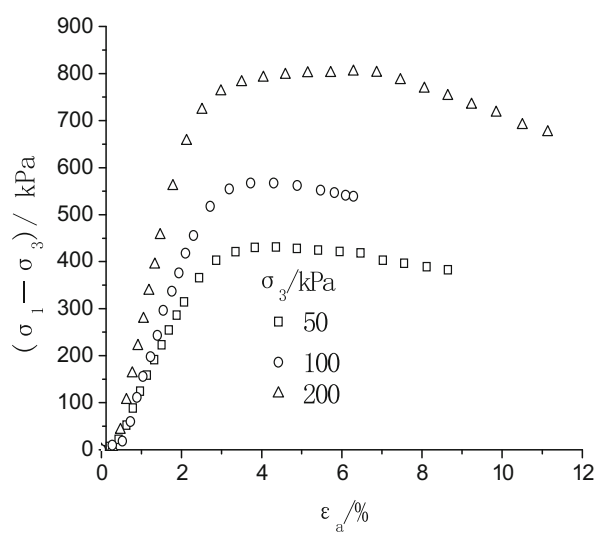

(b) $\mathrm{w}=13.5 \%$

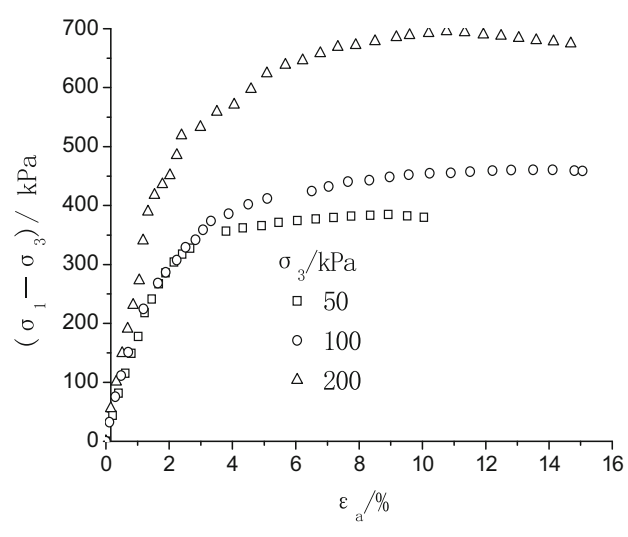

(d) $\mathrm{w}=16.02 \%$

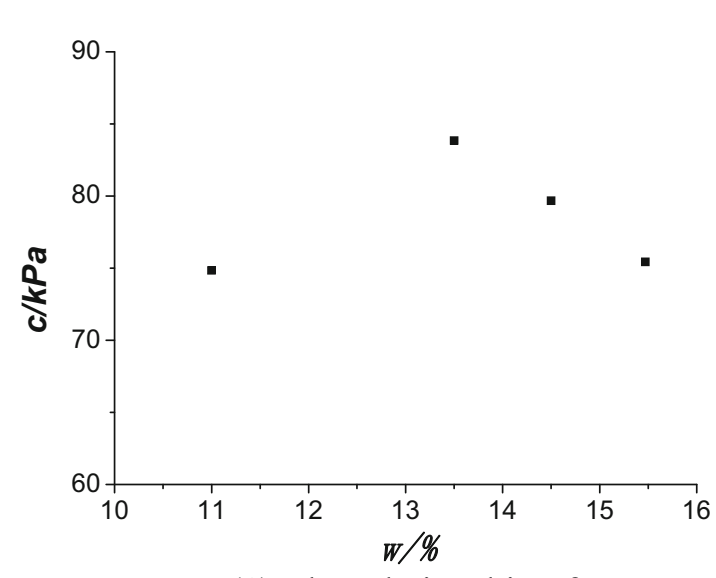

(1) The relationship of c-w

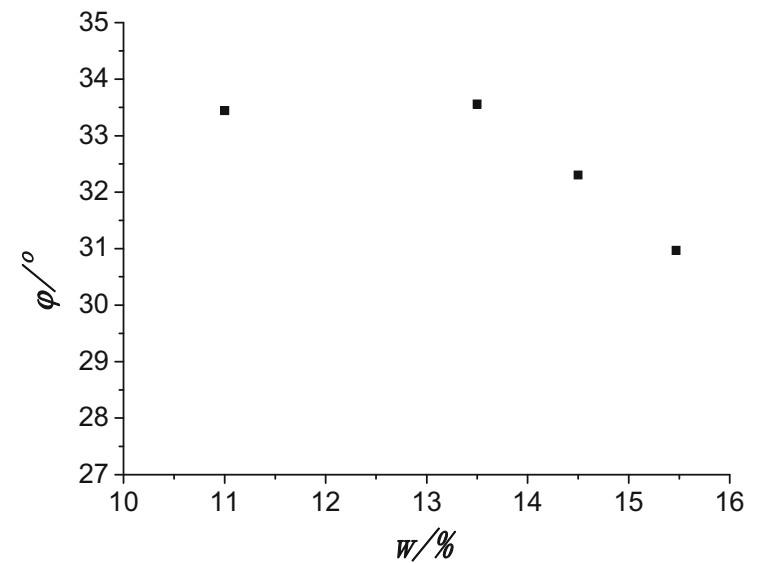

(2) The relationship of $\varphi-W$

Fig. 6 The relationships of water content with cohesion and internal friction angle. (1) The relationship of c-w. (2) The relationship of $\varphi-w$

There is a good explanation about the occurrence of peak value of pore water pressure and pore air pressure. When moisture content is lower than the optimum moisture content, air in the pore is more connective than water, the peak value of pore air pressure appears earlier than that of pore water pressure, as shown in (a) of
Fig. 8. And it is later than peak value of pore water pressure when moisture content is more than the optimum content, because of the connectivity of pore water, as in (c) and (d). They are up to the peak value at same time when the moisture content is the optimum content, as shown in (b). 


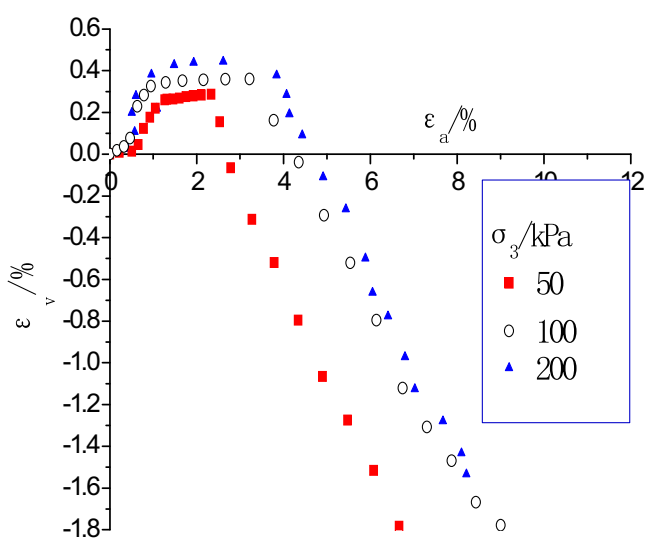

(a) $\mathrm{w}=11 \%$

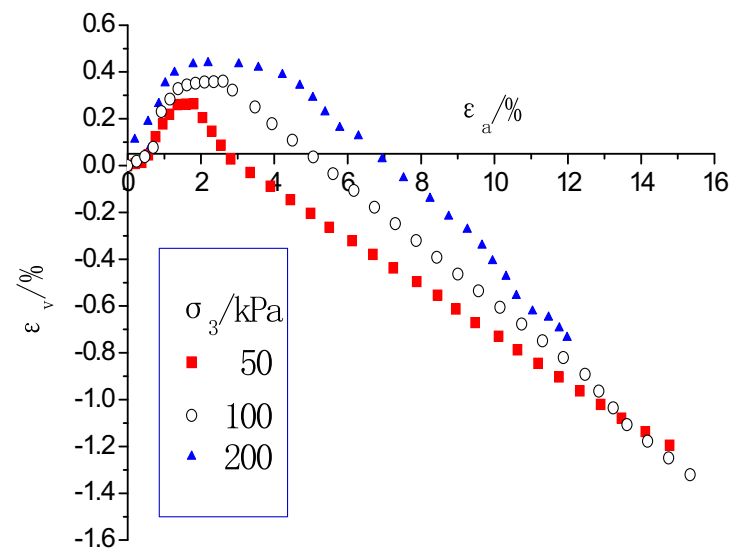

(c) $\mathrm{w}=14.83 \%$

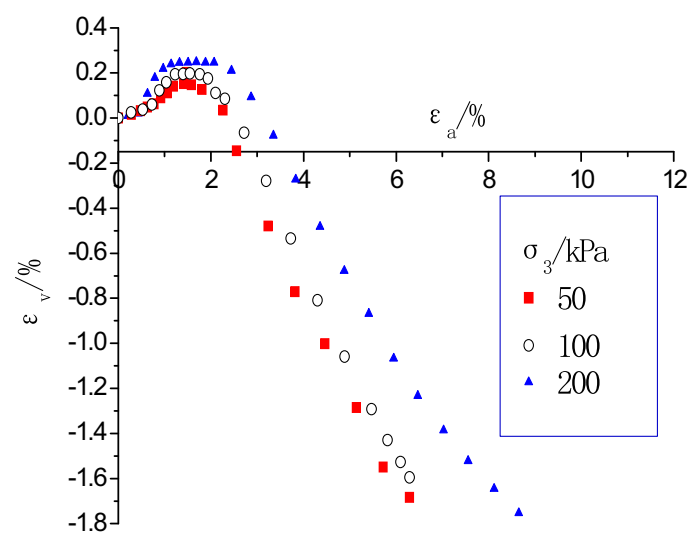

(b) $\mathrm{w}=13.5 \%$

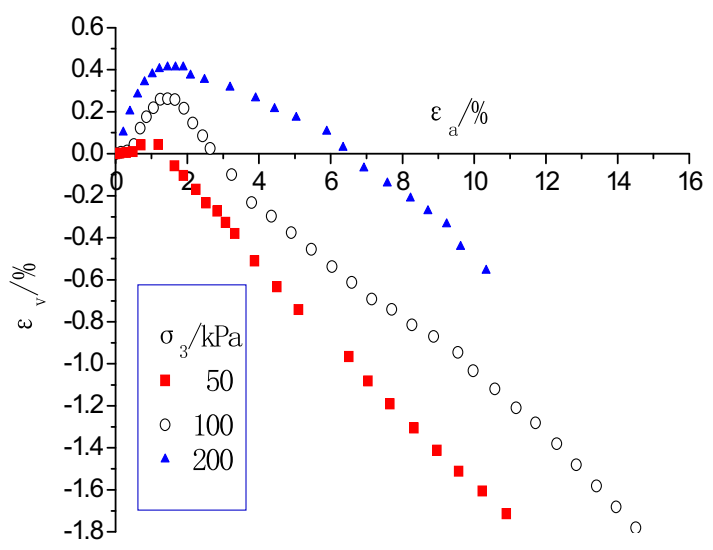

(d) $\mathrm{W}=16.02 \%$

Fig. 7 The curve of volume strain and axial strain at dry density of $1.85 \mathrm{~g} / \mathrm{cm}^{3}$

\section{Shear stress and suction relationship}

Figure 9 is the curve that shows, when the moisture content of $13.5 \%$ and the initial dry density of $1.85 \mathrm{~g} / \mathrm{cm}^{3}$, the relationship between shear stress and suction changes in the three different net confining pressure. Figure 9 shows that with the shear proceeding, the matrix suction increased first and then decreases after the dilation occurs. In the phase of shear contraction, the shear stress increases with the suction and the net confining pressure growth. The increasing trend is more obvious. The shear stress peak point in each curve is highlighted in Fig. 9. It shows that the maximum value of suction prior to the maximum value of the shear stress, other than corresponding to that point, which indicates that the matrix suction declines after dilation of soil, while shear stress continues to increase with the test proceeding. It will decrease after a certain value. In the same density and moisture content, the greater is the confining pressure, and the suction is correspondingly greater when shear failure occurs.

\section{Conclusions}

In this paper, a soil-water characteristic curve taking consideration of net mean stress was established. There is obvious difference between SWCC with and without net mean stress. When the suction is constant, the net mean stress has significantly affected on the soil-water characteristic curve shape, that is, the greater the net mean stress, the smaller moisture content of soil.

The shear feature of unsaturated soil under traffic load can be evaluated as properties in the state of non-drained and nonexhaust. The net confining pressure and moisture content have significant effect on the strength, deformation, and yield feature of unsaturated clayey sand. The strength is more at optimum moisture content. And it increases with net confining pressure growth in case of constant moisture content. The soil with same density is softening strain when moisture content is less than optimum content. Cohesion and friction angle of soil become larger with the increase of moisture content less than optimum content, while the water content is greater than the 


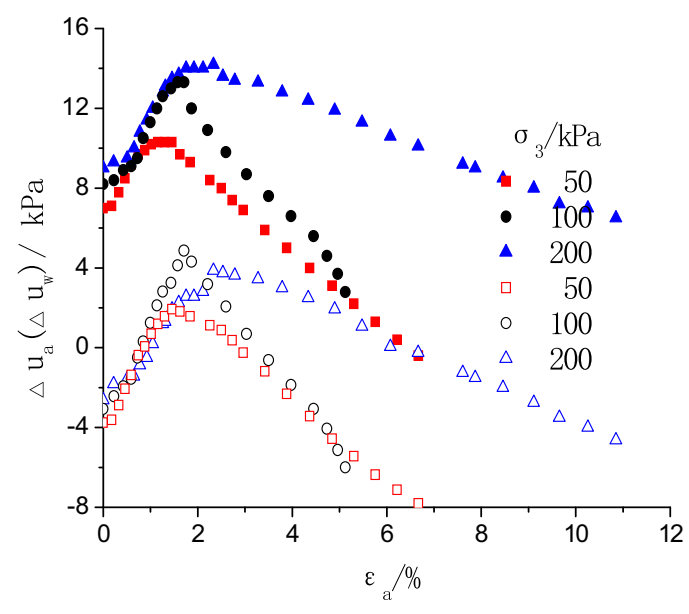

(a) $\mathrm{W}=11 \%$

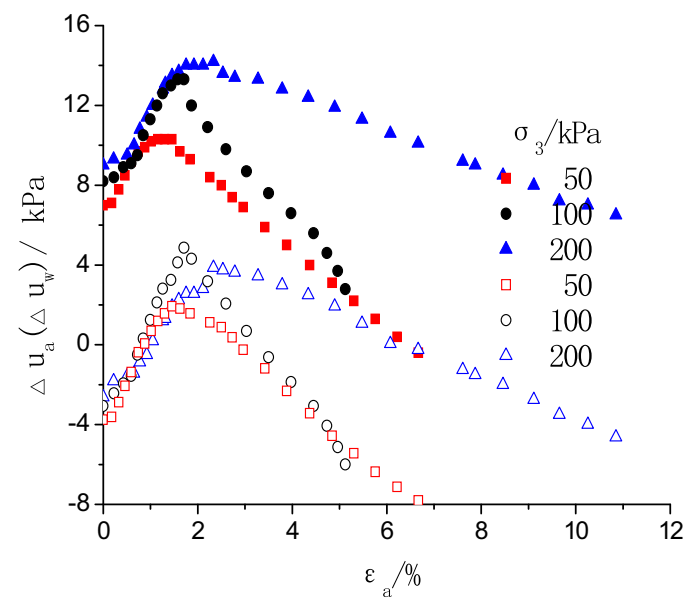

(c) $\mathrm{W}=14.83 \%$

Fig. 8 The pore pressure curve at initial dry density of $1.85 \mathrm{~g} / \mathrm{cm}^{3}$

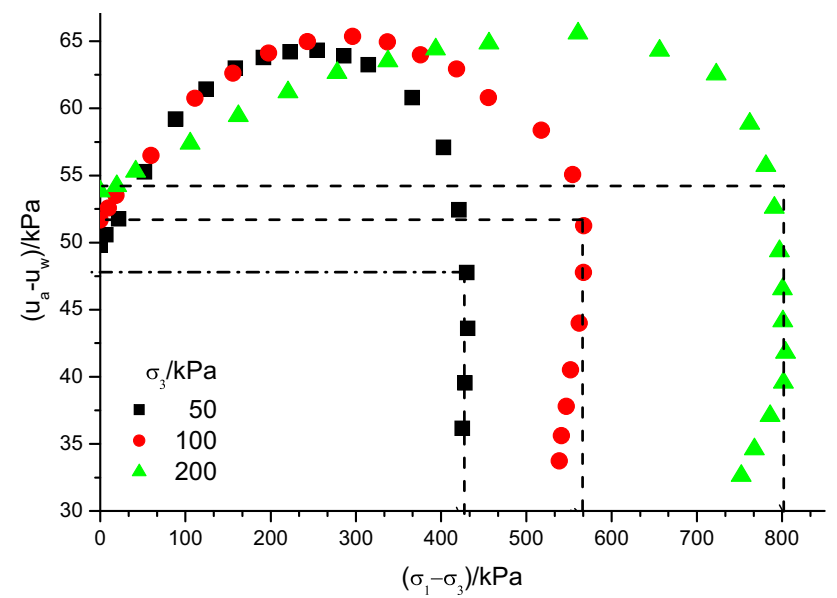

Fig. 9 The relationship between suction and shear stress at initial dry density of $1.85 \mathrm{~g} / \mathrm{cm}^{3}$ and moisture content $13.5 \%$

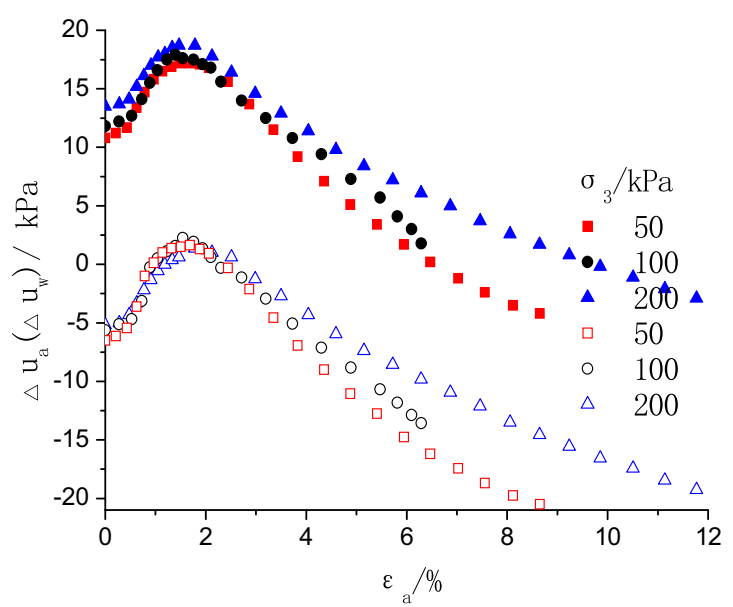

(b) $\mathrm{W}=13.5 \%$

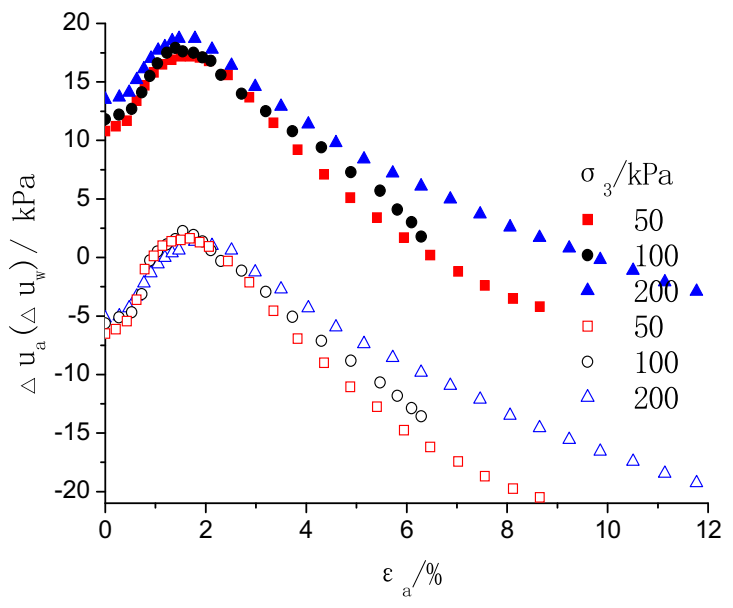

(d) $\mathrm{W}=16.02 \%$

optimum water content, they show the opposite trend. The unsaturated clayey sand shows obvious dilatancy in shearing, which significantly reduces with the net confining pressure increasing. And it is weakening as moisture content increases. Pore air pressure is closely related to the shear contraction of soil, which increases with shearing contraction and declines with dilation.

Acknowledgments The authors appreciate the support of the technology project of Guangdong Provincial Department of transportation (No. 200538).

\section{References}

1. Blatz JA, Graham J (2003) Elastic-plastic modelling of unsaturated soil using results from a new triaxial test with controlled suction. Géotechnique 53(1):113-122 
2. Chen Z, Zhou H, Fredlund DG (1999) Nonlinear model for unsaturated soils and its applications. Chin J Geotech Eng 21(5):603-608

3. Chen Z, Hu S, Sun S et al (2004) Development \& application of consolidation apparatus and direct shear apparatus for unsaturated soils. Chin J Geotech Eng 26(02):161-166

4. Fredlund DG, Xing AQ (1994) Equations for the soil-water characteristic curve. Can Gtech J 31(4):521-532

5. Fredlund, Rahadjo (1993) Soil mechanics for unsaturated soils. Wiley, New York

6. Huang H, Chen Z et al (2000) A study on yield locus of unsaturated soil on $\mathrm{p}-\mathrm{s}$ plane and soil-water characteristic curve. Rock Soil Mech 21(4):316-321

7. Miao L, Liu S, Lai Y (2002) Research of soil-water characteristics and shear strength features on Nanyang expansive soil. Eng Geol 65(4):261-267

8. Miao QQ, Zhang L, Chen ZH, Huang XF (2010) Experimental study of generalized SWCC of unsaturated sand and containing clay. Rock Soil Mech 31(1):102-106
9. Miao QQ, Chen ZH et al (2011) Strength, deformation and moisture change of unsaturated clayey sand. Chin J Undergr Space Eng 7(1):22-27

10. Guide RD (2002) American Association of State Highway and Transportation Officials. Washington, DC

11. Vanapalli SK, Fredlund DG, Pufahl DE et al (1996) Model for the prediction of shear strength with respect of soil suction. Can Geotech J 33(3):379-392

12. Vanapalli SK, Pufahl DE, Fredlund DG (1998) The effect of stress on the soil-water characteristic behavior of a compacted sandy-clay till. In: 51st Canadian geotechnical conference, Edmonton, pp 81-86

13. Zhang L, Miao Q, Chen $Z$ et al (2009) Triaxial test of deformation and strength change of a remolded unsaturated sand. J Logist Eng Univ 6:007 